\title{
The COVID 19 Pandemic: College Adolescents' Perception on School Reopening in Nigeria
}

\author{
Awoere T. Chinawa ${ }^{1}$, Josephat M Chinawa ${ }^{2}$, Edmund N Ossai ${ }^{3}$, Ann E Aronu $^{2} \&$ Vivian O Onukwuli ${ }^{2}$ \\ ${ }^{1}$ Consultant Community Physician and Lecturer Enugu state University Teaching hospital, Enugu State, Nigeria \\ ${ }^{2}$ Department of Paediatrics, College of Medicine, University of Nigeria Enugu Campus, Nigeria \\ ${ }^{3}$ Department of Community Medicine, College of Health Sciences, Ebonyi State University, Abakaliki, Nigeria \\ Correspondence: Ann E Aronu, Department of Paediatrics, College of Medicine, University of Nigeria Enugu \\ Campus, Nigeria. Tel: 234-803-722-1864.
}

Received: March 30, 2021 Accepted: May 9, 2021 Online Published: May 17, 2021

doi:10.5539/jedp.v11n2p29 URL: http://doi.org/10.5539/jedp.v11n2p29

\begin{abstract}
Background: Several colleges were closed in the wake of the COVID-19 pandemic. However, it is not clear if school closure has curbed the incidence of the infection.
\end{abstract}

Objectives: This study aimed to determine the perception of adolescent college students on school reopening and associated factors.

Methodology: This was a school-based cross-sectional study. A two-stage sampling technique was used to select five hundred adolescent college students from six secondary schools in the Enugu metropolis, Nigeria. Data were analysed with IBM Statistical Package for Social Sciences (SPSS) statistical software version 25.

Results: The mean age of the students was $15.1 \pm 1.7$ years and the majority, $56.4 \%$ were females. A higher proportion of the respondents, $78.0 \%$ were willing to return to school. For those not willing to return to school, the major reason was the preference for homestay until the pandemic is over, $57.3 \%$. The majority of the students, $67.6 \%$ had their learning improved during the pandemic. More than half of the students, $65.0 \%$ had online classes during the pandemic. Predictors of willingness to return to school amidst the COVID-19 pandemic included being a male student, (AOR=0.304, 95\% CI: 0.189-0.489), and being from a family of high socio-economic class, $(\mathrm{AOR}=0.363$, 95\% CI: 0.154- 0.855).

Conclusion: Closure of schools should be revisited, with enforcement of all preventive measures. Alternative methods for education such as e-learning seem to create a divide between the rich and the poor. It is therefore pertinent to develop a bridging plan to fill the gap created by this divide.

Keywords: College, adolescents, willingness, school, return, Nigeria

\section{Introduction}

The world health Organization on March 12, 2020, declared a pandemic, the coronavirus disease 2019 (COVID-19) outbreak, caused by severe acute respiratory syndrome coronavirus 2 (SARS-CoV-2). Furtherance to this, the United Nations Educational, Scientific and Cultural Organization (UNESCO) on March 18, 2020, documented school closures in 107 countries which affected 862 million children and adolescents. (WHO 2021; UN 2021) School closures are based on previous data from influenza outbreaks, where social contacts were reduced between students with consequent interruption of transmission. (Jackson, 2016)

Studies have shown that the closure of schools in the wake of a pandemic could reduce transmission and the number of cases, or create a negative impact by reducing the healthcare workforce. It is interesting to note that social mixing between children and adults and between children in different schools increases during holidays and school closures. It is therefore unclear whether school measures are even effective in coronavirus outbreaks. (Eames, Tilston, \& Edmunds, 2010; 2011) Coronavirus disease (COVID-19) is disrupting education especially among adolescents in college. Opening schools during the pandemic involves balancing health risks against the effects of interrupting learning. It is pertinent to note that COVID-19 infection in school children and adolescents (ages 3 to 18 years) is mostly asymptomatic or could present as a mild illness. (Ronan, 2020)

School reopening in the wake of the COVID 19 pandemic is a serious challenge with its attendant risks. It will be 
difficult to bring children together during the pandemic especially when vaccine trials are not yet concluded. This will create a huge number of hours lost in learning and acquiring knowledge (Mitchelle, 2020).

Some countries such as Taiwan had put in place a strong measure to combat coronavirus disease 2019 (COVID-19) and thus have reopened their schools for about 1.2 million students in the higher education system (Cheng et al., 2020).

Reopening of schools as well as preserving the health of the students and all personnel is paramount. In that light, best practices such as screening; diagnostic testing; isolation of cases; use of masks; and quarantine of contacts both within and outside the school environment are necessary. Transmission of the infection in the school must be quickly addressed. (Lyu, 2020)

Transmission within schools can be curbed by physical distancing, good ventilation, hand washing and masking. There is evidence that schools that implemented transmission mitigation measures recorded very minimal transmission rates (Cauchemez \& Valleron, 2020). School closure is the measure most often considered since the influenza pandemic and this has been seen to be effective in curbing transmission of disease (Jackson, 2016). However, school closure for months is associated with a high economic cost. In addition, the paucity of data on the role played by schools during these epidemics cast doubt on the effectiveness of school closure in reducing the impact of a pandemic. A joint data in France, documented that during holidays, there was a noted reduction in the rate of transmission of influenza by $20-29 \%$. Holidays were seen to prevent $18-21 \%$ of seasonal influenza cases in children. However, the impact of school closure would be minimal if low contact rates among children were not maintained for a prolonged period (Cauchemez \& Valleron, 2020).

Reopening of school is very important in that students will benefit from learning in the school than the use of the internet and other types of distant learning (Viner, 2020). The use of the internet during the pandemic may be very difficult for adolescents with disabilities. Besides virtual learning can create a risk of disparities in access to high-quality education in different socioeconomic groups.

Reopening schools is crucial especially now that the pandemic is declining. Data collected within the period of school resumption can be used to formulate policies for longer-term planning. As of the time of this report, there are several debates and speculations about whether schools should resume. Lack of trust in the government's ability to provide adequate preventive measures or appropriate precautionary measures against COVID, possible loss of loved ones to the menace if school reopens and fear of the unknown are factors militating the college students' willingness to return to school. There are few studies on maternal preferences of children returning to school, but much is not known about the perception/willingness of adolescent college students with regards to returning to school in the COVID 19 era. This study aimed to determine the perception of adolescent college students on school reopening and associated factors.

\section{Methods}

\subsection{Study Area}

Enugu is the administrative capital of Enugu state which is one of the five states in the southeast geo-political zone of Nigeria. Enugu metropolis is made up of three local government areas namely Enugu North, Enugu South, and Enugu East local government areas. The inhabitants of the metropolis are mainly of Igbo ethnic nationality with a mixture of other tribes. There are 33 public and 51 private secondary schools in the metropolis. The study was carried out in six secondary schools located in the Enugu metropolis.

\subsection{Study Design}

A cross-sectional study among adolescent college students attending secondary schools in Enugu metropolis. Information on demographic variables, class, and perception on school reopening was obtained using a validated self-administered questionnaire.

\subsection{Study Population}

Five hundred adolescent college students who fulfilled the inclusion criteria and who attended the six selected secondary schools were consecutively recruited in the course of the study over two months period. Adolescents who gave consent, who was present at the time of study in the selected secondary schools, who was in exam class (JSS3 and SS3) (these were the ones who were allowed to be in school as at the time of the study) were included in the study while those who did not give consent were excluded.

\subsection{Sample Size Determination}

The minimum sample size for the study was determined using the sample size formula for simple proportions. (Wu 
\& McGoogan, 2020) A sample size of 500 students was included in the study based on a type 1 error $(\alpha)$ of 0.05 . a tolerable margin of error of 0.05 and a prevalence of $50 \%$ being the estimated proportion of adolescents willing to return to school amidst the COVID-19 pandemic.

\subsection{Sampling Technique}

A two-stage sampling technique was used to select the students for inclusion in the study. The list of schools in the three local government areas in Enugu metropolis, Nigeria, was made and ranked in terms of the number of students in the schools. (There are 33 public secondary schools and 51 privately owned secondary schools in the metropolis). This was done separately for public and private secondary schools in each of the three local government areas. The first six schools based on this ranking in each of the three local government areas were remarked. Then, using a simple random sampling technique of balloting, one public and one private secondary school were selected from each of the three local government areas in the metropolis. This served as the first stage.

In the second stage, a list of all students in senior secondary class three and junior secondary class three was made. (These two classes were the ones permitted by the Government of Nigeria to go back to school and write their terminal examinations amidst the COVID-19 pandemic). The number of students in the two classes in the six selected schools from school records was 1963. This served as the sampling frame. Sampling interval was obtained by dividing this number by the sample size of 500 , hence a sampling interval of 4 was used. So every $4^{\text {th }}$ student was recruited for the study, based on the sitting arrangement of the students on each day of data collection. The index student on each day of data collection was selected using a simple random sampling technique of balloting

\subsection{Ethical Consideration and Consent}

Ethical clearance was sought and obtained from the Ethics Committee of University of Nigeria Teaching Hospital Ituku-Ozalla, Enugu, Nigeria. Permission and consent were also obtained from the school principals and adolescents from the schools of study respectively. Consent was also sought and obtained from their parents or guardians of the students.

Participation in the study was voluntary. Respondents' anonymity and confidentiality were maintained.

\subsection{Data Analysis}

Data entry and analysis were done using IBM Statistical Package for Social Sciences (SPSS) statistical software version 25. Categorical variables were summarized using frequencies and proportions while continuous variables were summarized using mean and standard deviation. Chi-square test of statistical significance and multivariate analysis using binary logistic regression were used in the analysis. The level of statistical significance was determined using a $p$-value of $<0.05$.

The outcome measure of the study was the willingness of the respondents to return to school amidst the COVID-19 pandemic. This was assessed by the response of the respondents to the question of whether they were willing to return to school should the schools re-open now.

In determining the factors that affect willingness to return to school amidst COVID-19 pandemic, variables that had a $\mathrm{p}$ value of $<0.2$ on bivariate analysis were entered into the logistic regression model to determine predictors of willingness to return to school. The result of the logistic regression analysis was presented using adjusted odds ratios at $95 \%$ confidence intervals and the level of statistical significance was determined by a $p$ value of $<0.05$.

Knowledge of the spread of COVID-19 was assessed using five variables. For each respondent, a correct answer was assigned a score of one while an incorrect answer was given a score of zero. Respondents that correctly answered $\geq 60 \%$ of the five variables were regarded as having good knowledge of spread of COVID- 19 while those that scored less than $60 \%$ were classified as having poor knowledge.

Preventive practices against COVID-19 were assessed using ten variables. For each of the variables, a correct answer was given a score of one and an incorrect answer a score of zero. Respondents that correctly answered $\geq 60 \%$ of the ten variables used to assess preventive practices against COVID-19 were regarded as having good preventive practice while those that scored less than $60 \%$ were classified as having poor preventive practice.

The socio-economic class of the respondents was determined by combining

The socio-economic class of the parents of the respondents was determined using the educational attainment of the mother of the respondent and the occupation of the father. This was computed by adding the educational attainment of the mother and the occupation of the father of the respondent based on the scoring system of the scale and diving the sum by 2 . After division, a score of 1 was regarded as high socio-economic class, 2 and 3 middle socio-economic class. A score of 4 and 5 placed the respondent in low socio-economic class. 


\section{Result}

Table 1 shows the socio-demographic characteristic of the respondents. The mean age of the respondents was $15.1 \pm 1.7$ years. A minor proportion of the respondents, $43.6 \%$ were males. Similarly, a minor proportion of the respondents, $35.2 \%$ were in senior secondary class three. The majority of the fathers of the respondents, $63.2 \%$ have attained secondary education.

Table 1. Socio-demographic characteristics of respondents

\begin{tabular}{llc}
\hline Variable & $\begin{array}{l}\text { Frequency } \\
(\mathbf{n}=\mathbf{5 0 0})\end{array}$ & Percent (\%) \\
\hline Age of respondents & $15.1 \pm 1.7$ & \\
Mean \pm (SD) & & \\
\hline Age of respondents in groups & 211 & 42.2 \\
$<15$ years & 289 & 57.8 \\
$\geq 15$ years & & \\
\hline Gender & 218 & 43.6 \\
Male & 282 & 56.4 \\
Female & & \\
\hline Educational attainment of Father & 20 & 4.0 \\
No formal education & 120 & 24.0 \\
Primary education & 44 & 8.8 \\
Secondary education & 316 & 63.2 \\
Tertiary education & & \\
\hline Employment status of Mother & 32 & 6.4 \\
Unemployed & 254 & 50.8 \\
Self-employed & 214 & 42.8 \\
Salaried employment & & 35.0 \\
\hline Class of study & 324 & 64.8 \\
Junior secondary class three & 176 & 35.2 \\
Senior secondary class three & 197 & \\
\hline Socio-economic class & & \\
High socio-economic class & & \\
Middle socio-economic class & & \\
Low socio-economic class & & \\
\hline & & \\
\hline
\end{tabular}

Table 2 shows a willingness to return to school amidst COVID-19 among the respondents. A higher proportion of the respondents, $78.0 \%$ were willing to return to school. The major reasons for being willing to return to school include regaining lost academic grounds, $49.5 \%$ and being tired of homestay, $25.1 \%$. For those not willing to return to school, the major reasons included a preference for homestay until pandemic is over, $57.3 \%$ and to avoid unnecessary exposure, $25.1 \%$. The majority of the students, $67.6 \%$ had their personal learning improved during the pandemic. The majority, $65.0 \%$ had online classes during the pandemic. 
Table 2. Willingness to return to school amidst COVID-19 among the respondents

\begin{tabular}{|c|c|c|}
\hline Variable & $\begin{array}{l}\text { Frequency } \\
(\mathbf{n}=\mathbf{5 0 0})\end{array}$ & Percent (\%) \\
\hline \multicolumn{3}{|l|}{ Willingness to return to school } \\
\hline Yes & 390 & 78.0 \\
\hline No & 110 & 22.0 \\
\hline Reason for being willing to return to school & $(n=390)$ & \\
\hline Need to recover lost academic grounds & 194 & 49.7 \\
\hline Tired of staying at home & 98 & 25.1 \\
\hline Schools will likely initiate good preventive measures & 43 & 11.0 \\
\hline Ability to adopt good preventive measures at school & 29 & 7.4 \\
\hline Lack of adequate care at home & 26 & 6.7 \\
\hline Reason not willing to return to school & $(\mathrm{n}=110)$ & \\
\hline Prefer to remain at home until pandemic is over & 63 & 57.3 \\
\hline Avoid unnecessary exposure to COVID-19 & 23 & 20.9 \\
\hline Limited financial resources in the family & 13 & 11.8 \\
\hline The school may not initiate good preventive measures & 11 & 10.0 \\
\hline Personal studying increased during the lockdown & $(\mathrm{n}=500)$ & \\
\hline Yes & 338 & 67.6 \\
\hline No & 162 & 32.4 \\
\hline
\end{tabular}

Table 3 shows the perception of government response to the COVID-19 pandemic by the respondents. The majority of the respondents, $80.6 \%$ felt government response to the pandemic was effective. The major ways the students intend to reduce the effect of the COVID-19 pandemic on other children included educating them on COVID-19 and its prevention. 
Table 3. Factors affecting willingness to resume school amidst COVID-19 pandemic among the respondents

\begin{tabular}{|c|c|c|c|c|}
\hline \multirow{2}{*}{ Variable } & \multicolumn{2}{|c|}{ Willingness to return to $\operatorname{school}(m=500)$} & \multirow{2}{*}{$\chi^{2}$} & \multirow{2}{*}{ p value } \\
\hline & Yes N (\%) & No N (\%) & & \\
\hline \multicolumn{5}{|l|}{ Age of respondents in groups } \\
\hline$<15$ years & $156(73.90$ & $55(26.1)$ & 3.518 & 0.061 \\
\hline$\geq 15$ years & $234(81.0)$ & $5(19.0)$ & & \\
\hline \multicolumn{5}{|l|}{ Gender } \\
\hline Male & $142(65.1)$ & $76(34.9)$ & 37.265 & $<0.001$ \\
\hline Female & $248(87.9)$ & $34(12.1)$ & & \\
\hline \multicolumn{5}{|l|}{ Educational attainment of Father } \\
\hline Tertiary education & $232(73.4)$ & $84(26.6)$ & 10.507 & 0.001 \\
\hline Secondary education and below & $158(85.9)$ & $26(14.1)$ & & \\
\hline \multicolumn{5}{|l|}{ Employment status of Mother } \\
\hline Unemployed & $23(71.9)$ & $9(28.1)$ & 3.813 & 0.149 \\
\hline Self-employed & $207(81.5)$ & $47(18.5)$ & & \\
\hline Salaried employment & $160(74.8)$ & $54(25.2)$ & & \\
\hline \multicolumn{5}{|l|}{ Class of study } \\
\hline Junior secondary class 3 & $256(79.0)$ & $68(21.0)$ & 0.550 & 0.458 \\
\hline Senior secondary class 3 & $134(76.1)$ & $42(23.9)$ & & \\
\hline \multicolumn{5}{|l|}{ Socio-economic class } \\
\hline High socio-economic class & $118(67.4)$ & $57(32.6)$ & 21.088 & $<0.001$ \\
\hline Middle socio-economic class & $158(80.2)$ & $39(19.8)$ & & \\
\hline Low socio-economic class & $114(89.1)$ & $14(10.9)$ & & \\
\hline \multicolumn{5}{|c|}{ Knew someone infected with COVID-19 } \\
\hline Yes & $32(71.1)$ & $13(28.9)$ & 1.368 & 0.242 \\
\hline No & $358(78.7)$ & $97(21.3)$ & & \\
\hline \multicolumn{5}{|c|}{ Knowledge of spread of COVID-19 } \\
\hline Good knowledge & $168(79.2)$ & $44(20.8)$ & 0.338 & 0.564 \\
\hline Poor knowledge & $222(71.1)$ & $66(22.9)$ & & \\
\hline \multicolumn{5}{|c|}{ Preventive practices against COVID-19 } \\
\hline Good preventive practices & $270(78.0)$ & $76(22.0)$ & FT & 1.0 \\
\hline Poor preventive practices & $120(77.9)$ & $34(22.1)$ & & \\
\hline
\end{tabular}

FT Fishers exact test.

Table 4 shows factors affecting willingness to resume school amidst the COVID-19 pandemic among the respondents. A higher proportion of females, $87.9 \%$ were willing to return to school when compared with the males and the difference in proportions was found to be statistically significant, $\left(\chi^{2}=37.265, \mathrm{p}<0.001\right)$. A significantly higher proportion of respondents whose fathers have attained secondary education and below, $85.9 \%$ were willing to return to school when compared with those whose fathers have attained tertiary education, $73.4 \%$ $\left(\chi^{2}=10.507,0.001\right)$. Of the highest proportion of respondents whose parents were in the lower socio-economic class, $89.1 \%$ were willing to return to school when compared with those in the upper socio-economic class, $67.4 \%$ and the difference in proportion was found to be statistically significant, $\left(\chi^{2}=21.088, \mathrm{p}<0.001\right)$. 
Table 4. Predictors of willingness to return to school amidst COVID-19 pandemic among the respondents

\begin{tabular}{|c|c|c|c|c|}
\hline \multirow{2}{*}{ Variable } & \multirow{2}{*}{ Adjusted odds ratio } & \multirow{2}{*}{ p value } & \multicolumn{2}{|c|}{ 95\% Confidence interval } \\
\hline & & & Lower & Upper \\
\hline \multicolumn{5}{|l|}{ Age of respondents in groups } \\
\hline$<15$ years & 0.956 & 0.849 & 0.601 & 1.520 \\
\hline$\geq 15$ years & 1 & & & \\
\hline \multicolumn{5}{|l|}{ Gender } \\
\hline Male & 0.304 & $<0.001$ & 0.189 & 0.489 \\
\hline Female & 1 & & & \\
\hline \multicolumn{5}{|l|}{ Educational attainment of Father } \\
\hline Tertiary education & 0.857 & 0.636 & 0.453 & 1.622 \\
\hline Secondary education and below & 1 & & & \\
\hline \multicolumn{5}{|l|}{ Employment status of Mother } \\
\hline Unemployed & 0.622 & 0.299 & 0.254 & 1.524 \\
\hline Self-employed & 0.939 & 0.800 & 0.570 & 1.543 \\
\hline Salaried employment & 1 & & & \\
\hline \multicolumn{5}{|l|}{ Socio-economic class } \\
\hline High socio-economic class & 0.363 & 0.020 & 0.154 & 0.855 \\
\hline Middle socio-economic class & 0.602 & 0.175 & 0.570 & 1.543 \\
\hline Low socio-economic class & 1 & & & \\
\hline
\end{tabular}

\section{Discussion}

Studies suggest that THE COVID 19 infection poses little or no health risks to children under the age of 18 years (She, L. Liu, \& W. Liu, 2020). For instance, in the United States and some other parts of the world, fewer cases of COVID-19 were reported in children between the ages of zero to seventeen (Bialek et al., 2020). A recent study has documented a prevalence of $7.3 \%$ out of all cases of COVID-19, among the children. Furthermore, hospitalization rates in children have been reported to be lower than in adults. (Wu, 2020, 2012)

It is seen from this study, that a higher proportion of college adolescents, $78.0 \%$ were willing to return to school. The major reason for their willingness to return to school is to enable them to regain lost academic grounds. The few students who would not like to return to school stated reasons for opting out of school at the moment; ranging from "fear of being exposed unnecessarily to the pandemic" to "preference to study at home until the pandemic is over". Some also stated a lack of trust in the schools' ability to provide adequate preventive measures against THE COVID 19, as their reason.

Studies available have shown that, not only do children and adolescents rarely fall ill following the infection, when they do, the infection is less severe than in adults. Studies in China have shown that adolescents play a very little role in the transmission of the virus, not only to adults but even to other children and adolescents (CDC, 2020; U.S. Census Bureau 2020; Chidini et al., 2020). Adolescents are more capable of actively understanding and conforming to specific hygiene rules when compared to younger children, so reopening schools will not cause more harm than good (Chidini et al., 2020). Furthermore, it has been suggested that adolescents suspected of having been infected with SARS-CoV-2 should be tested immediately to either confirm or rule out such an infection (Chidini et al., 2020).

This study has also shown that a large number of students have started online classes organized by their schools during the pandemic using mainly Zoom and Google meet. However, they stated that this has not been regular. The irregularity noted in these online classes was caused mainly by lack of internet services, lack of electronic devices, and irregular supply of power. The fact that this study was undertaken in urban and semi-urban areas, where many parents in the upper socio-economic class live, could explain the high proportion of students participating in online education in this study. 
Though closing schools and transitioning to online learning is important in the event of a Lockdown, as occasioned by the COVID 19, studies conducted in the US have shown that many American children live without essential internet services. According to current data from the National Telecommunications and Information Administration (NTIA), it is noted that 3.1 million households (14.1\%) with school -aged children have no internet connection at home. Though some of these families may have a wireless subscription, data plans are insufficient for effective and prolonged online learning (Peter, 2020)

It has been documented that an estimated $40 \%$ of the poorest countries failed to provide internet services for students during the COVID-19 crisis (UIS fact sheet 2016). In addition, domestic chores, especially for the girl child, and household errands, and even farm work, can also prevent children from getting sufficient learning time at home. [20] Adolescents who are living with disabilities are already at a disadvantage especially those who are mentally retarded. (UNESCO, 2020)

A study in the Gaza strip showed that despite efforts by the government to use online teaching, adolescents in the Gaza strip were not satisfied with this method of teaching as they do not allow for dynamic interactions and social interaction (UNFPA, 2016). Furthermore, limited access to the internet and frequent power outages were also commonly reported as factors militating against their learning in the lockdown period in Uganda. Ugandan adolescents noted that being in school is not the same as learning at home (UNFPA, 2016).

A 13-year male adolescent in Gaza during an interview said: 'Regular education is much better, [now] teachers send us questions and we answer them, but the teacher does not look at our answers and doesn't provide feedback, what stupidity is this?'. (UNFPA, 2016)

This study revealed that adolescents whose parents were from low socio-economic class and whose fathers attained secondary education, $89.1 \%$ and $85.9 \%$ respectively, were willing to return to school when compared with those in the upper socio-economic class, $67.4 \%$ and $73.4 \%$ respectively. Furthermore, adolescents whose parents were in the high socio-economic class were about three times less likely to be willing to return to school when compared with those whose parents were in the lower socio-economic class. Students from the low socio-economic classes are noted to have less opportunity and limited access to the internet compared with their peers from the high socioeconomic class (The UNO, 2020)

This finding can be explained by the fact that poverty limits access to learning at home, especially concerning online learning. Furthermore, school closures are known to affect the social, educational and psychological development of children and adolescents, as well as cause the loss of parental jobs and income, especially in the low socioeconomic class family. Some studies have also noted that children from low-income backgrounds are more likely to be more adversely affected than children from high-income backgrounds. (UNESCO, 2020).

It is also important to note that findings from the Global Partnership for Education (GPE) showed that the total number of children especially those of low socioeconomic class not returning to their education after school closures is on the rise.

A higher proportion of females, $87.9 \%$ were willing to return to school when compared with males. This can be explained by the fact that school closures make the adolescent females more vulnerable to child marriage, sexual and emotional abuse and gender-based violence. This reflects the ripple effect of school closure on adolescents. Studies have suggested that some female children from low-income parents may swing back to home and never come back again to continue their education Global Partnership for Education (GPE, 2020). School closure has posed some deleterious effects on adolescents, especially to the girl child. For instance, school closure in the Gaza Strip has negatively affected adolescent females, especially older ones, who take education as the key for their self-esteem, self-reliance and future career. (UNFPA, 2016)

Adolescents of older age and higher grades were willing to return to school compared to the younger ones and those in lower grades as seen in this study. That older adolescent child wants to conclude their college, which has long been stalled by the pandemic, and are desirous to get into their new phase of life, as well as face a new task in the university could explain this difference.

The majority of the college adolescents, $80.6 \%$ felt government response to the pandemic was effective. This could also enhance prompt school reopening. This finding was also reported in a study that showed increased government efforts towards school reopening.

\section{Conclusion}

Continued closure of schools should be revisited with a view to school reopening when all preventive measures are in place and being enforced. Alternative methods for education such as e-learning seem to create a divide between 
the rich and the poor. It is therefore pertinent to develop a bridging plan to fill the gap created by this divide.

\section{Data Availability Statement}

This will be made available by the authors, at any time.

\section{Ethical Consideration and Consent}

Ethical clearance was sought and obtained from the ethics committee of University of the Nigeria Teaching Hospital Ituku-Ozalla, Enugu, Nigeria. Permission and consent were also obtained from the school principals and adolescents from the schools of study respectively. Participation in the study was voluntary. Respondents' anonymity and confidentiality were maintained.

\section{Author Contributions}

JMC and AEA conceived the study, drafted the manuscript, and gave final approval of the version to be published. ENO, AEA, VOO, ATA and JMC collected and interpreted the data, revised the manuscript critically for important intellectual content, and gave final approval of the version to be published. ENO analysed the data. All authors approved the final version of the manuscript.

\section{Funding}

We were not funded by any organization. The authors funded the research.

\section{Conflict of Interest}

The authors declare no conflict of interest

\section{Acknowledgments}

We are grateful to Miss Carol for helping in entering the raw data.

\section{References}

Bialek, S., Gierke, R., Hughes, M., McNamara, L. A., Pilishvili, T., \& Skoff, T. (2020). CDC COVID-19 Response Team. Coronavirus disease 2019 in children-United States, February 12-April 2, 2020. Morbidity and Mortality Weekly Report, 69(14), 422. https://doi.org/10.15585/mmwr.mm6914e4

Cauchemez, S., Valleron, A. J., Boëlle, P.-Y., Flahault, A., \& Ferguson, N. M. (2008). Estimating the impact of school closure on influenza transmission from Sentinel data. Nature, 452(7188), 750-754. https://doi.org/10.1038/nature06732

CDC. Demographic Trends of COVID-19. Retrieved September 27, 2020, from https://www.cdc.gov/covid-data-tracker/index.html\#demographics

Cheng, S. Y., Wang, C. J., Shen, A. C. T., \& Chang, S. C. (2020). How to safely reopen colleges and universities during COVID-19: experiences from Taiwan. Annals of Internal Medicine, 173(8), 638-641. https://doi.org/10.7326/M20-2927

Chidini, G., Villa, C., Calderini, E., Marchisio, P., \& De Luca, D. (2020). SARS-CoV-2 infection in a pediatric department in Milan: a logistic rather than a clinical emergency. https://doi.org/10.1097/INF.0000000000002687

Eames, K. T. D., Tilston, N. L., White, P. J., Adams, E., \& Edmunds, W. J. (2010). The impact of illness and the impact of school closure on social contact patterns. Health technology assessment (Winchester, England), 14(34), 267-312. https://doi.org/10.3310/hta14340-04

Eames, K. T., Tilston, N. L., \& Edmunds, W. J. (2011). The impact of school holidays on the social mixing patterns of school children. Epidemics, 3(2), 103-108. https://doi.org/10.1016/j.epidem.2011.03.003

Global Partnership for Education (GPE). (2020). Opinion: Don't let girls' education be another casualty of the $\begin{array}{lllll}\text { coronavirus. } & \text { Retrieved } & \text { May } & 1, & \text { from }\end{array}$ https://www.globalpartnership.org/news/opinion-dont-let-girls-education-be-another-casualty-coronavirus

Jackson, C., Vynnycky, E., \& Mangtani, P. (2016). The relationship between school holidays and transmission of influenza in England and Wales. American journal of epidemiology, 184(9), 644-651. https://doi.org/10.1093/aje/kww083

Kaffenberger, M. (2021). Modelling the long-run learning impact of the Covid-19 learning shock: Actions to (more than) mitigate loss. International Journal of Educational Development, 81, 102326. https://doi.org/10.35489/BSG-RISE-RI_2020/017 
Li, X., Xu, W., Dozier, M., He, Y., Kirolos, A., \& Theodoratou, E. (2020). The role of children in transmission of SARS-CoV-2: a rapid review. Journal of global health, 10(1). PMID: 32612817; PMCID: PMC7323934. https://doi.org/10.7189/jogh.10.011101

Lordan, R., FitzGerald, G. A., \& Grosser, T. (2020). Reopening schools during COVID-19. https://doi.org/10.1126/science.abe5765

Lu, X., Zhang, L., Du, H., Zhang, J., Li, Y. Y., Qu, J., ... \& Wong, G. W. (2020). SARS-CoV-2 infection in children. New England Journal of Medicine, 382(17), 1663-1665.

Lyu, W., \& Wehby, G. L. (2020). Community Use of Face Masks And COVID-19: Evidence From A Natural Experiment Of State Mandates In The US: Study examines impact on COVID-19 growth rates associated with state government mandates requiring face mask use in public. Health affairs, 39(8), 1419-1425. https://doi.org/10.1377/hlthaff.2020.00818

She, J., Liu, L., \& Liu, W. (2020). COVID-19 epidemic: disease characteristics in children. Journal of medical virology, 92(7), 747-754. PMID: 32232980; PMCID: PMC7228385. https://doi.org/10.1002/jmv.25807

U.S. Census Bureau. (2020). Retrieved September 27, 2020, from https://www.census.gov/quickfacts/fact/table/US/AGE295219\#AGE295219externalicon

UNESCO Education: From disruption to recovery. (2020). Retrieved September 26, 2020, from https://en.unesco.org/covid19/educationresponse

UNESCO, Global Education Monitoring (GEM) Report, 2020: Inclusion and education: all means all, 2020. (2020). Retrieved September 26, 2020, from https://www.worldbank.org/en/news/immersive-story/2019/01/22/pass-or-fail-how-can-the-world-do-its-ho mework

UNFPA. (2016). Palestine 2030. Demographic Change: Opportunities for Development. Palestine: UNFPA.

United Nations Educational Scientific and Cultural Organization COVID-19 educational disruption and response. (2020). $\quad$ Retrieved September $\quad 21, \quad 2020, \quad$ from https://en.unesco.org/themes/education-emergencies/coronavirus-school-closures

Viner, R. M., Russell, S. J., Croker, H., Packer, J., Ward, J., Stansfield, C., ... \& Booy, R. (2020). School closure and management practices during coronavirus outbreaks including COVID-19: a rapid systematic review. The Lancet Child \& Adolescent Health, 4(5), 397-404. https://doi.org/10.1016/S2352-4642(20)30095-X

Walger, P., Heininger, U., Knuf, M., Exner, M., Popp, W., Fischbach, T., ... \& Simon, A. (2020). Children and adolescents in the CoVid-19 pandemic: Schools and daycare centers are to be opened again without restrictions. The protection of teachers, educators, carers and parents and the general hygiene rules do not conflict with this. GMS hygiene and infection control, 15. Retrieved September 27, 2020, from http://uis.unesco.org/sites/default/files/documents/new-methodology-shows-258-million-children-adolescen ts-and-youth-are-out-school.pdf

WHO Director-General's opening remarks at the Mission briefing on COVID-19. (2020). Retrieved September 21, 2020, from https://www.who.int/dg/speeches/detail/who-director-general-s-opening-remarks-at-the-missionbriefing-on-covid-19

\section{Copyrights}

Copyright for this article is retained by the author(s), with first publication rights granted to the journal.

This is an open-access article distributed under the terms and conditions of the Creative Commons Attribution license (http://creativecommons.org/licenses/by/4.0/). 